\title{
The use of Dynamic Assessment by Educational Psychologists in the UK
}

\section{Ruth Deutsch and Yvonne Reynolds}

Psychology and Special Needs, Institute of Education, University of London, 25 Woburn Square, London WC1H OAA, UK

\begin{abstract}
Training in Dynamic Assessment (DA) was rarely available in the UK until 1994. This is the first study to explore the outcomes of its availability in terms of the practice of DA and perceptions about it among educational psychologists (EPS). One hundred and nineteen EPs who had taken positive steps to inform themselves about DA by undertaking some degree of training or by joining a DA interest group, were surveyed to explore the extent of their initial training in DA, subsequent use of it and issues of implementation. Overall, the 88 responses (74\%) received suggest, among those surveyed, widespread awareness of DA as a model of cognitive assessment and positive attitudes to it, coupled with a low level of implementation. The low level of use was frequently attributed to insufficient training in DA, to lack of time due to other assessment priorities, often set by the Local Education Authority, and to lack of the ongoing expert support felt to be necessary to maintain use of a demanding form of assessment. The authors take the position that the EP's repertoire would be enriched by improved knowledge of and training in DA. The research raises important issues for cognitive assessment, and also raises the broader question whether there is a need for a more proactive involvement of educators in enhancing the cognitive functioning of children.
\end{abstract}




\section{Introduction}

Interest in Dynamic Assessment (DA) as a means of cognitive assessment of children has grown considerably in the UK in recent years (Stringer et al., 1997). DA is based on an approach to the development of cognition in children, and to the role of adults in that development, which differs in a number of important ways from psychometric approaches to assessment.

\section{Psychometric and dynamic models of assessment}

Psychometric assessment seeks to measure the intelligence of individuals by means of their performance on a set of tasks at a given point in time and to predict future performance from such measurement. Its basis and purpose is the quantification of differences between individuals of similar ages. In order to secure this objective, it is important that the assessor intervenes as little as possible during the performance of the tasks. Socio-cultural variables which may affect this performance - for example the way in which a parent's or teacher's contribution to a child's cognitive development may have influenced it - are not considered to be of fundamental importance. Similarly the quality and quantity of past learning experiences are not the focus of interest.

In Dynamic Assessment the goal of assessment is very different. By contrast with the psychometric approach, the child's current level of performance is not the focus of interest. The assessor's objective is rather to understand, from the way in which a child learns to improve their performance in the course of given cognitive tasks. In order to achieve this detailed understanding, the assessor must interact with the child during the performance of the tasks. 


\section{Theoretical basis of DA}

The theoretical roots of Dynamic Assessment lie in Vygotsky's socio-cultural theory of child development, (Vygotsky, 1986) in which the role of the parent, carer, teacher, sibling, or peer, in interacting with the individual child, is seen as fundamental to the formation and growth of cognitive skills, which are culturally mediated through these interactions. Cultural mediation is essential in the development of intelligence. Cultural tools - the physical, communicative and representational means by which a given society is characterised - are mediated to the child, and their appropriation by him or her, reflected in their cognitive functioning, is the outcome of such mediation. In a related strand of Vygotskian theory, the concept of the Zone of Proximal Development (ZPD) (Vygotsky, 1986) provides a conceptual framework from which diverse routes in research and application have developed. The ZPD is defined as the extent to which a child can perform with assistance what they cannot perform alone. The key characteristic of DA derived from this concept of assisted performance is the interaction which occurs within an assessment, which is justified from a socio-cultural conception of intelligence where the possibility of change is a defining feature. Thus intelligence is seen as a dynamic rather than fixed characteristic. Adults and children are viewed as open systems capable of more effective and efficient learning throughout life, and this process is seen as inseparable from the development of intelligence. Children learn and are taught cognitive skills not only through their direct encounters with stimuli in their environment, but also through adult mediation.

Assessments based on adult mediation represent intensive, time-limited interactions, where the assessor is not looking for the average performance of a child, but is searching for samples of maximal performance as an indication of his/her ZPD and is also seeking means to help him/her to move through it. 
Seen in its theoretical context, DA is a broad approach, not a set of specific tests. The psychologist's goal is one of identifying what cognitive skills need developing and strengthening in a child (and this can be conveyed, for example, in the format of an Individual Education Plan), the cognitive requirements of given types of task (which can inform differentiation of the curriculum for the child) and advising upon and supporting the teaching of the child. This will be direct teaching of cognitive skills, as well as of traditional curriculum content. This micro-analysis focuses on the three 'partners in the learning process': the child, the task and the mediator (typically parents or teachers). DA aims to help optimise, through understanding the interplay of these essential elements, the match between the learner and the curriculum on offer.

\section{DA models}

The nature of the assessment procedure varies between different DA models. A typical DA procedure may involve three phases, a pre-test, teaching, and post-test, in which interaction takes place in the teaching or learning phase. Some DA models use a series of graduated prompts (Carlson and Wiedl 1980; Campione et al., 1984) where the assessor intervenes first at a minimal level and then with increasing teaching support, if required, in order to achieve success on the tasks of the test. Here, the stages and content of the intervention are predetermined and still retain some characteristics of standardisation allowing for responses of different children to be compared. Examples of recent European DA models using this approach are those of Guthke \& Wingerfeld (1992), Guthke (1995) and Paour (1992).

A different model within the DA approach is that of the Mediated Learning group, which is exemplified in the DA models of Feuerstein (1979), Haywood (1992), Lidz (1991) Tzuriel(1997) and Kahn (1992). In these models, intervention during the assessment is not standardised at all and is totally responsive to the individual needs of the child. The use of 
three phases (test/teach/test) may also be at the discretion of the assessor. The Mediated Learning models are sometimes described as 'clinical' DA intervention, because they are highly responsive to individual need and lead to diagnostic and prescriptive insights which are uniquely relevant to a particular child. The assessor mediates cognitive strategies to the child (Haywood, 1992) rather than teaching the child better task performance on a specific test item. In such models, key components affecting the child's learning needs are identified by means of detailed analysis of the assessor's intervention. (Lidz, 1991). The analysis is of (i) within-child cognitive factors, such as the child's use of 'intellective' skills, (e.g. their ability to make comparisons, to conserve, and to generate and test hypotheses), as well as non-'intellective' aspects such as habits, attitudes and degree of motivation (ii) the component cognitive demands of each assessment task; and (iii) the content of the assessor's mediation. The modality in which the task is presented, (for example verbal, visual, numerical, pictorial) the level of complexity, the task content, and the specific cognitive skills required for successful performance, are the assessor's analytical tools which are deliberately manipulated in response to the behaviour of the child in the test situation. All the child's responses are noted, and the insights gained can result in useful recommendations for teachers and parents.

\section{Dynamic Assessment in the UK}

Although dissatisfaction with psychometric methods of assessment was being expressed as early as the 1920's (Buckingham 1921), serious development of DA did not take place until the 1970's. The exception to this general picture was the work of Feuerstein (1979) who began to develop the Learning Potential (or Propensity) Assessment Device (LPAD) in the early 1950 's in response to the need to assess and place within the education system, refugee children whose learning experiences had been limited or disrupted by wartime trauma and cultural dislocation. His work remained an isolated example of a non-psychometric approach 
to assessment until the DA studies of the 1970's and 80's (Budoff \& Corman1976; Carlson \& Wiedl 1980; Campione et al.,1984).

The Mediated Learning DA model, (an example of which is Feuerstein's LPAD ,1979, 1986) may be said to be the only fully dynamic model of assessment (Haywood, 1992) in that it does not measure task outcomes, but rather attempts to teach cognitive strategies for problem solving - strategies which are conceived as domain-independent (Missiuna \& Samuels 1988).

Distinguishing among different DA models is relevant to EP practice in the UK because the most widely known to UK EPs are those of Mediated Learning which have in general been developed from the specific theories of Feuerstein; for example those of Tzuriel, Lidz and Haywood. The analysis of cognitive functions through the LPAD (mediational intervention), is the only DA analytical tool that has been made available to EPs to date in the UK- and that to a very limited extent - in initial or in in-service training. Case history studies such as those of Stringer et al., (1997) and Birnbaum \& Deutsch (1996) use the LPAD approach as a means of analysing the cognitive functions of the child. Indeed, the interest in Dynamic Assessment shown by coverage in this journal and that of the Division of Educational and Child Psychology of the British Psychological Society (BPS) (Birnbaum \& Deutsch 1996) has been largely engendered by DA training provided in the UK for EPs, and with the exception of brief courses given by Feuerstein and his colleagues in the 1980s, these have all taken place since 1994.

\section{Wider implications}

It will be evident from the comprehensive reach of the socio-cultural perspective which is the theoretical basis of DA, that the assessment process is part of a very much wider terrain. That terrain involves consideration of what the purposes of education are considered to be, how 
education is organized in support of those purposes, and how the system views and provides for the cognitive development of children. The perspective as a whole poses a challenge to some current views of education, such as emphasis on curriculum content without an equivalent emphasis on the processes of learning or on the acquisition of metacognitive skills. Moreover other current educational goals, such as the achievement of inclusive education, pose a similar challenge. Changes to the assessment 'end' of the system should be seen as part of this context of challenge and undoubtedly will have far-reaching implications.

\section{Aim of the study}

This study followed up the experiences of EPs who had had some form of training in DA between 1994 and 1999. Its purpose was to investigate how effective the EPs perceived the training to be, to what extent they subsequently used DA in their professional practice, and what they saw as the advantages and problems of DA in the UK educational psychology context.

\section{Method}

The sample

A questionnaire designed to assess knowledge of, practice of, and views about DA was sent by mail to 119 EPs working in Britain today. The sample of EPs was not random, but was composed of those who in one way or another had already expressed an interest in DA. It was felt that the sample would be sufficiently large to enable some generalisation about issues concerning DA among those EPs who had taken positive steps to seek information about it. The sample was composed from mailing lists containing the names of EPs who had attended DA courses in various parts of the country and those of members of the DA national interest group. In addition, a general letter was sent to The Psychologist, the journal of the BPS and to 
the newsletter of the Association of Educational Psychologists (AEP) requesting interested psychologists to contact the researcher. (There were only three responses to the BPS and AEP approaches.)

\section{Piloting of the questionnaire}

The questionnaire was piloted in order to ensure that it was brief and consistent with accessing desired information, that it did not embody prior assumptions about the nature of training or practice in DA, that it did not assume acquaintance with any specific DA method, and that it covered those issues in DA which EPs with knowledge of the technique felt to be the most important. Piloting was by discussion of an initial version with a group of five EPs who all used DA, by postal invitation to five additional EPs who were also asked to comment on the initial version, and by means of an in-depth, semi-structured interview with one EP who regularly practised DA. The questionnaire was amended to take account of the views obtained.

\section{The questionnaire}

\section{Questionnaire on Dynamic Assessment (DA)}

This questionnaire is designed to find out from Educational Psychologists about their knowledge / experience with Dynamic Assessment. All responses will be treated as confidential and anonymous. Your name will not be used. Please do fill in your name at the top of the questionnaire, simply for me to know who has responded.

\section{Name:}

Please answer the questions and feel free to add any further comments on DA at the end of the questionnaire.

Please tick box

1 a) Are you

1. An EP working for a Local Education Authority 
2. An EP working privately

3. An EP working elsewhere e.g. a voluntary organization

4. Other

b) How many years have you been working as an EP?

1. $0-2$

2. $3-5$

3. $6-10$

4. 11-15

5. $16-20$

6. $20+$

7. not applicable

2 a) How did you come to hear about DA?

1. Read about it

2. From a friend / colleague

3. In EP core training

4. From a general INSET

5. From a special INSET on DA

6. Other

b) Approximately how long have you been practising DA?

1. less than one year

2. 1-3 years

3. 4-6 years

4. $7+$

5. not applicable

3 a) Are you presently using DA in your job as an EP?

1. Yes

2. No

3. $N / A$ 
If yes, please specify

1. less than 2 hours per week

2. $2-5$ hours per week

3. $2-5$ hours per month

4. 6-10 hours per month

5. more than 10 hours per month

4 a) Which theoretical basis do you use in your DA work?

1. Feuerstein (MLE)

2. Brown and Campione (graduated prompts)

3. Other (perhaps your own) - please state

4. None

b) Which DA materials do you use?

1. The LPAD (Feuerstein)

2. D. Tzuriel's materials (e.g. the CATM)

3. Carol Lidz's approach

4. A combination of approaches

5. Other (perhaps your own) - please state

5 a) Have you received training/INSET in DA?

1. Yes

2. No

If Yes, can you give brief details?

b) Did you find this training useful to your work?

1. Yes

2. No

c) Was the training adequate in meeting your professional goals

1. Yes

2. No

3. Partly 
Please explain.

6 a) Do you receive any ongoing support in using DA?

1. Yes

2. No

If Yes, is the support:

1. From a supervisor

2. From a DA support group

3. From a peer support group in your place of work

4. Other

b) In general do you think support is needed to maintain practice in DA?

1. Yes

2. No

7. In general, are you satisfied with your present use of DA?
3 Yes
$4 \quad \mathrm{No}$
5. $\mathrm{N} / \mathrm{A}$

If No, are there any circumstances preventing you from using DA as much as you would like?

8 a) What do you see as the major advantages of DA? Can you list two or three?

b) What do you see as the major disadvantages of DA? Can you list two or three?

Any additional comments you would like to make?

Thank you for taking the time to fill out this questionnaire 


\section{Results and discussion}

Of the 119 questionnaires distributed, 88 were returned giving a response rate of $74 \%$.

\section{Employment}

Eighty-five percent of respondents were employed by a Local Education Authority (LEA). The remaining $15 \%$ were self-employed, not currently practising as an EP, worked for nonstatutory agencies, or held academic positions. Somewhat surprisingly, therefore, given that Dynamic Assessment is not considered a 'mainstream' form of assessment, the great majority of EPs in this sample work for their local authority.

Table I: Years of experience of EPs $(n=88)$

\begin{tabular}{|l|c|}
\hline EPs in practice for less than 2 years & $16 \%$ \\
\hline EPs in practice from 3 to 5 years & $25 \%$ \\
\hline EPs in practice from 6 to 10 years & $19.5 \%$ \\
\hline EPs in practice for 11 years and more & $37.5 \%$ \\
\hline
\end{tabular}

Table I shows that, despite the fact that training in Dynamic Assessment has only recently become more widely available in the UK, the majority of those who have expressed an interest or who have taken up training opportunities are not those who are newest to the profession, but rather those with more experience as EPs.

Table II shows that more than one-half the EPs in the sample, despite having been chosen as a result of active interest in DA, have only heard or read about DA. Less than half the respondents have had direct access to any form of training in it. More particularly, although the BPS encourages introduction to a broad range of assessment techniques in the core training of EPs, less than one-quarter of the sample had been introduced to DA within their initial professional training. In the case of the longest-serving EPs, this may have been because information about DA was not available in core training at the time of initial training. 
Table II: Sources of information about DA $(n=88)$

\begin{tabular}{|l|c|}
\hline Read about it & $32 \%$ \\
\hline Heard about it from a friend / colleague & $21.8 \%$ \\
\hline EP core training & $24 \%$ \\
\hline General INSET & $4.5 \%$ \\
\hline Specific INSET on Dynamic Assessment & $13.64 \%$ \\
\hline Some other source & $4.5 \%$ \\
\hline
\end{tabular}

Almost without exception, however, respondents indicated a present need for greater DA training provision.

Table III: Length of time the EPs had been using DA $(n=88)$

\begin{tabular}{|l|c|}
\hline Less than 1 year & $25 \%$ \\
\hline Between 1 and 3 years & $27.5 \%$ \\
\hline Between 4 and 6 years & $6.89 \%$ \\
\hline Non-users & $39 \%$ \\
\hline
\end{tabular}

Table III shows that fifty-nine percent of the respondents had used DA (which included, therefore, some who had not been formally trained). The rest, although interested in the technique, had not used it at all. This is no doubt a reflection of the fact that more than onehalf the EPs in the sample (Table II), while having read or heard about DA, had received no DA training.

Over one-half of the users had been implementing DA for 3 years or less. Thus, a large majority of DA users in the UK are new to the field. A supplementary question confirmed that $53 \%$ of respondents currently used DA, indicating that a small proportion, $6 \%$, have ceased using this form of assessment.

Figure 1: Time spent per week on Dynamic Assessment 


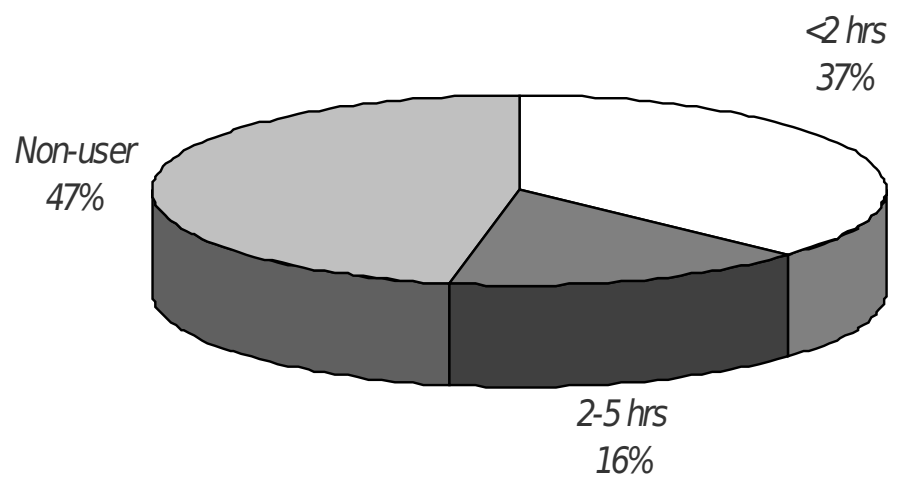

Figure 1 shows the extremely low level of use of DA among interested EPs. This may be due in part to lack of time overall for assessment of pupils, and to the fact that DA is a timeconsuming form of assessment. Two recent studies of EP use of time, that of Thomson (1998) in Scotland and of Imich (1999) in the UK generally, consider, respectively, the time allocated to casework and more generally to schools. Neither identifies assessment as a separate category. However, Imich reports $39 \%$ of EP time spent in schools, and Thomson notes that EPs report doing less casework than they had done previously. If time spent in schools and casework are considered to include time spent on assessments, then a relatively small proportion of an EP's time is likely to be available for assessment. Responses to our questionnaire indicate that EPs are not happy with this situation.

Theoretical bases and materials used.

Of the EPs in the sample who acknowledged a theoretical basis for their DA work or for their knowledge of DA ( $60 \%$ in all), the majority identified Feuerstein's theories (Feuerstein \& Feuerstein 1991), including the theory of Mediated Learning Experience (41\%). The remainder identified Campione \& Brown's (Campione et al. 1984) Vygotskian-based 
approach (9\%) or selected the category: 'Other, (perhaps your own)' (10\%). By contrast, of the $62 \%$ of respondents who answered the question 'Which DA materials do you use?' the majority (45\%) said that they used a combination of materials. Few used Feuerstein's (1986) LPAD (3.4\%), and equal small proportions (7\% in each case) used Tzuriel's materials (Tzuriel 1997b) or the materials of Lidz (1991), both of whom have taught brief workshops in the UK within the last three years. Ten per cent used other materials. One possible explanation for this pattern is the fact that no one set of materials available to DA users can be considered suitable for the entire age-range. There is some indication that a few of those choosing the category 'Other' have attempted to use psychometric tests such as the British Ability Scales dynamically, although this is not recommended by leading practitioners (Haywood \& Tzuriel 1992; Lidz 1991).

\section{$D A$ training received}

Seventy-one percent of the respondents who responded to this item indicated that they had received some kind of DA training. Of these, roughly equal proportions had attended an introductory session less than one day in length (22\%), had attended a 3-day workshop (or up to three individual days) (22\%) or had undertaken training courses of five days or more $(26 \%)$

\section{Usefulness of DA training to EPs and issues of continuing support}

Ninety-four per cent of those who responded to this item (about one third did not respond) answered 'yes' to the question whether they had found the training they had received useful in their work, indicating that they had found something of value in what they had seen or heard. However, of those who answered the supplementary question 'Was the training adequate to 
meet your professional goals?' the majority responded either 'Partly' or 'No'. Table IV shows the proportions.

Table IV: 'Was your DA training adequate to meet your professional goals?' $(n=62)$

\begin{tabular}{|l|l|}
\hline Yes & $21.8 \%$ \\
\hline No & $13.8 \%$ \\
\hline Partly & $34.5 \%$ \\
\hline
\end{tabular}

Most of those who responded to this item wrote comments which clarified their response, many of them expanding on why they had responded 'partly'. The clarifications they offered are classified in Table V.

Table V: Reasons why DA training mostly did not meet EPs' requirements $(n=62)$

\begin{tabular}{|l|c|}
\hline Insufficient basic training & $39 \%$ \\
\hline $\begin{array}{l}\text { Lack of follow up support and } \\
\text { supervised practice }\end{array}$ & $24 \%$ \\
\hline Difficulty in integration into practice & $10 \%$ \\
\hline Training experience positive & $14 \%$ \\
\hline Other & $13 \%$ \\
\hline
\end{tabular}

Overall approximately one-half the respondents commented on the training they had received and, of these, over three-quarters indicated that their needs were at best only partly met.

- No-one who had had less than three days training in DA considered the training to be adequate.

- Of those who had taken a three-day course (20 respondents) only three users were able to practice at what they regarded as a satisfactory level.

- Of the 18 respondents who had undertaken the longest UK training (five to fifteen days), by contrast, 17 stated that they were able to practice with confidence and several had gone on to share their skills with other EPs. 
Beyond the issue of initial training, there was near-unanimity (99\%) that follow-up support and practice was necessary in addition to training.

\section{Reasons why continuing support is felt to be needed}

EPs' comments indicated four groups of reasons why support was needed after initial training:

- Early on, support for first attempts to implement the new skill is required. At a later stage, advice is needed on how DA materials are best used as well as guidance on the new ways of observing children's functioning which DA requires and on interpreting what is seen. It is also seen as very important that EPs are helped to develop report-writing formats which, in the context of DA, reflect the individual needs of a child, make practical recommendations, communicate clearly to parents and to other professionals, and are not too time-consuming.

- DAis very different in character and implementation from the score-yielding standardised testing which many schools associate with EPs' assessments of children. The rationale and advantages of DA need to be explained in ways that will lead to its acceptance, and EPs consider that support in doing this is needed.

- The outcome of a DA is likely to result in recommendations for classroom practice which do not slot neatly into the headings of National Curriculum subjects. EPs must devise ways of helping teachers to implement these recommendations and indicated that they need advice and support in doing this.

- An EP may be the only one in the service who is using DA. In the absence of a peer group of DA users and expert support, an EP may become discouraged and use of DA becomes difficult to maintain. 
These and other comments conveyed a real feeling of regret among the EPs surveyed that the difficulties they encountered prevented them from being able to use DA as much as they wished.

\section{Support actually received}

Only 22 EPs reported receiving any kind of expert support following initial training in DA. Of these, seven said they belonged to a DA support group, twelve reported getting some support from a peer group in their place of work, and 3 reported other forms of support such as team meetings. No-one referred to regular support. A few mentioned unsuccessful efforts to provide a support forum. A major difficulty is that very few people are available in the UK with sufficient experience of DA to act as advisors or facilitators of support groups, and many local authorities at the present time have no such person they can call on.

\section{Reasons for EPs' dissatisfaction with the extent of their current use of DA}

Only $12.5 \%$ of respondents were satisfied with the current extent of their use of DA. The categories of classification for reasons for dissatisfaction and for the advantages and disadvantages of DA were established after independent allocation by three classifiers. The reasons given for dissatisfaction fell into seven broad categories. The proportions of respondents in each are set out in Table VI.

Constraints of roles and responsibilities. These included management responsibilities within an EP or team, course tutorships or academic posts.

Table VI: Reasons for EPs' dissatisfaction with the extent of their current use of DA

\begin{tabular}{|l|c|}
\hline Constraints of roles and & $5.7 \%$ \\
\hline Local Authority attitudes & $17 \%$ \\
\hline Time & $21.5 \%$ \\
\hline
\end{tabular}




\begin{tabular}{|l|c|}
\hline Training & $25 \%$ \\
\hline Supervision and support & $22.7 \%$ \\
\hline Resources and materials & $9 \%$ \\
\hline No problems & $5.7 \%$ \\
\hline
\end{tabular}

Local Authority attitudes. There was pressure from Local Education Authorities to perform standardised psychometric tests for statutory assessments, and, in general, a demand for test scores as measures of academic potential. EPs were seen as number providers and by schools as 'resource getters', and not as having a role in intervention. A comment which summed up the spirit of many was: 'Psychometrics is seen as secure...expectations need to be changed and this includes schools as well, who regard EPs as score suppliers, but not as contributing anything to intervention in getting children to learn more effectively’.

Time constraints. This was a very frequently stated reason for failure to practice DA to the extent desired. Constraints were due to large caseloads, insufficient time allocated to schools and to work with individual children and the extra time required for DA when compared with other forms of assessment.

Training needs. Difficulty in accessing initial training was the most frequently stated reason for restricted use of DA, sometimes due to budget restrictions, and lack of confidence to practice following insufficient initial training. EPs felt that DA training needed to be a Continuing Professional Development priority.

Lack of supervision and ongoing support. This was also very frequently stated as a reason for failure to begin or to maintain practice of DA. 
Resources and materials. Comments in this category were about difficulty in accessing materials and difficulty in working with them. These issues can be seen as interrelated with those concerning time and budget constraints, and with training inadequacies.

No constraints on practice. Of the five EPs who did not report any constraints on their practice, one was a neuro-psychologist, two were in private practice (hence free of constraints associated with LEA budgets and policies) and three had taken a leadership role in promoting the training and practice of Dynamic Assessment, and so must have challenged and overcome difficulties encountered by many of their colleagues. These three had all undertaken the fullest available training, had sought to pass on the skills they had acquired to teachers or to other EPs, had offered peer support, and had joined a national DA network or forum.

Perceived advantages of $D A$. The fact that more EPs (71) responded to this item than had used Dynamic Assessment reflects the interest in its principles that was aroused by hearing or reading about it. Very varied responses were grouped into seven categories. The proportions of responses in each category are set out in Table VII.

Table VII Advantages of Dynamic Assessment ( $n=88)$

\begin{tabular}{|l|c|}
\hline Flexibility & $9 \%$ \\
\hline Positive for child and EP & $46.6 \%$ \\
\hline Interactive & $14.8 \%$ \\
\hline Practical - advice for teachers & $51 \%$ \\
\hline Alternative to psychometrics & $21.6 \%$ \\
\hline Rich in information & $20.5 \%$ \\
\hline More culture-fair & $4.5 \%$ \\
\hline
\end{tabular}

Flexibility. A number of respondents commented on the flexibility of the Dynamic Assessment process. This included the freedom to select materials, to adjust tests, to vary 
interventions, styles of intervention and the responses of the assessor according to the needs of the child.

Positive for the child and the EP. Many EPs saw DA as enhancing the self-esteem of the child by enabling him/her to see himself/herself as a person who could rather than could not learn, as looking for strengths rather than weaknesses and for maximal rather than average performance. (Some referred explicitly to the zone of proximal development.) DA was perceived as 'a student-friendly approach'. It was seen as showing 'positive directions for future development rather than a deficit model' and as being 'a more challenging way for an EP to work with a child'.

Interactive. Some EPs specifically used this word to describe an advantage of DA, and indeed it fundamentally distinguishes the process of DA from that of standardised testing.

Provides practical advice for teachers. The largest group of responses fell into this category. DA was seen as indicating to parents and teachers concrete 'next steps' in learning for a child, generating ideas to help, and providing strategies. 'Offers down to earth and usable advice for teachers and SNAs as a direct result of assessment' was a typical comment.

Alternative to psychometrics. The existence of an alternative to a psychometric approach was seen as an advantage. DA was also described as "more realistic" or simply "superior".

Rich in information. Included in this category were comments on specific aspects of Dynamic Assessment which give information not easily obtained in other ways. These included the Cognitive Map (used for task analysis), the use of mediational strategies (seen as 
able to give information about a child's learning needs and the type of intervention required on the part of the assessor and later by the teacher) and the analysis of cognitive functions which can help identify 'barriers to learning'.

More culture-fair. A few comments described DA as less culturally biased and as nondiscriminatory.

\section{Perceived Disadvantages}

Again, the number (70) of responses indicated that some were from EPs who did not practice DA. There was a wide variety of responses. Table VIII sets out the numbers of responses in each class.

Table VIII: Disadvantages of Dynamic Assessment $(n=88)$

\begin{tabular}{|l|c|}
\hline Time & $30.7 \%$ \\
\hline Language of DA & $14.8 \%$ \\
\hline Linking DA to the curriculum and classroom practice & $24 \%$ \\
\hline Non standardised - subjective & $19.3 \%$ \\
\hline Insufficient research & $12.5 \%$ \\
\hline DA materials & $11.3 \%$ \\
\hline LEA demands & $20.5 \%$ \\
\hline No major disadvantage & $5.7 \%$ \\
\hline
\end{tabular}

Time. The amount of time needed for assessment, report-writing and feedback was the most frequently noted disadvantage of DA.

Language. The vocabulary and concepts used in DA were considered to make communication with parents and teachers difficult. 
Links to classroom practice. DA was seen as difficult to link to classroom practice. It is interesting to recall that the possibility of such linkage was seen by other EPs as one of its adavantages.

Subjective. DA was seen as being too open to individual interpretation. Thus the flexibility seen as an advantage by some EPs was seen by others as a weakness.

Insufficient evaluation. Some EPs felt there was insufficient research on long-term outcomes of DA intervention or comparing DA with standardised tests in terms of usefulness.

DA materials. DA materials were criticised as being either inaccessible or too expensive.

LEA demands. LEA preference for standardised test scores was seen as a disadvantage of DA. Again what was seen by some EPs as an advantage (DA's individualised, diagnostic approach) was seen by others as a drawback in the light of LEA constraints.

No major disadvantages. Five EPs saw no major disadvantages, provided attention was given to adequate practice, involving teachers and providing support for EPs.

\section{Discussion}

Of a membership of approximately 2000 EPs reported by the Association of Educational Psychologists in 1999, the 119 EPs to whom this questionnaire was sent probably represent a majority of those who have taken positive steps to inform themselves about DA, either by joining an interest group, or through some kind of training. Of these, only 58\% identified 
themselves as DA users. Indications are, therefore, that current use of DA by most EPs in the UK is very limited.

Many EPs in our sample were attracted by DA's commitment, by contrast with psychometric models, to the assessment of learning potential, a positive interaction between EP and child, and to what they saw as its more culture-fair approach in a multi-cultural environment. They also considered that it offered increased opportunities to demonstrate psychological and analytical skills and to link assessment to intervention. Nevertheless, $41 \%$ had not used it at all in their work. The study suggests that it was lack of training opportunities and expert support that produced this outcome, indicating a substantial unmet need. Hardly any respondents complained about the quality of the training received, but they felt that it was insufficient. Although some EPs who followed only a 3-day course did report practising DA, the same EPs also reported lack of confidence to interpret and use DA materials, write reports or give advice about classroom intervention on the basis of a DA assessment. Indeed nearly two-thirds of those who responded 'partly' to the question whether the training they received was adequate for their professional needs - including many who received more than 3 days training - felt there was a need for longer training and more followup support, including supervised practice, which would enable them to put DA concepts into operation. A particular issue raised by some of the most active DA users was the difficulty of adapting DA concepts, as presented in training, to the UK educational context. This reported difficulty could be as a result of insufficient understanding on the part of practitioners, and therefore difficulty in "bridging" the concepts into classroom practice, or could be indicative of a more fundamental problem, that is whether the cognitive functions analysed in a DA approach and the mediational strategies used by the assessor are in some way untranslatable into content curriculum. The present limited level of DA training and experience does not yet enable us to address these important questions and impeded the wider understanding of 
DA that would inform discussion of them. Such discussion is essential because DA is based on a different paradigm from that on which psychometric tests are based. It poses a challenge to traditional psychometric assessment models and to the expectations of many school psychological services.

\section{Availability of suitable training}

Why has adequate UK training in DA been in such short supply? According to this study, the best-known approach to Dynamic Assessment among British psychologists is that of Feuerstein, who has not encouraged training in his Learning Potential Assessment Device or access to its materials outside Israel. Courses which have been available in the UK have largely been the result of invitations to other prominent figures in the Mediated Learning approach to Dynamic Assessment such as Carol Lidz and David Tzuriel who have introduced their own materials to British EPs. Such courses have not, however, in the opinion of the present authors, offered a sufficiently thorough foundation training to enable EPs to use the analytical concepts and the materials effectively. What would be required is training in the theoretical basis of DAand in the skills of analysis it requires, followed by an introduction to a range of possible tests by means of which the analytical tools (the key tools of DA) can be applied. Opportunities to practice DA under supervision should be a component of practitioner training. This extended type of training was undertaken by those EPs in the study who were the most confident and experienced in the use of DA If Feuerstein's theoretical approach is the one most widely associated with Dynamic Assessment by British EPs is that of Feuerstein, then training in it should be more widely available within the UK. Experts visiting from overseas may act as catalysts, but long-term growth is only likely to result from the work of skilled local trainers who are thoroughly familiar with the UK educational context. In this situation, better initial training would be more likely to lead to 
more confident practice, resulting in a group of experienced professionals able to support newly-trained EPs. Giving feedback on assessments to teachers and parents and of involving them in intervention would also become easier.

\section{LEA and school attitudes}

Many EPs saw 'LEA demands for scores' (as one response succinctly put it) as a barrier both to wider acceptance of the theoretical approach of DA and to allocation of the time necessary to undertake this type of assessment. Schools too, according to some respondents, do not see the EP's role as that of offering expert advice on meeting the teaching and learning needs of students, but rather as that of the LEA representative who is called in to make student assessments on the basis of which the school can get the resources it needs. The effects of the latter perception is regretted by many of the EPs who participated in this survey. The enormous pressures on LEA officers, school managers and teachers should be borne in mind here, however, and the perceptions of these survey participants do not in themselves indicate that these education staff would in principle be unwilling to consider the perspectives offered by DA. In general, EPs have been able to develop their professional practice through innovation even in the context of considerable difficulties, and they have often managed to negotiate their roles and tasks to the benefit of such development. Building on this experience, EPs have a potentially pivotal role to play. In advising school policy-makers on the one hand and devising with teachers concrete classroom strategies on the other, they are at an interface which offers the possibility of real influence on how children's cognitive development is understood and how this is reflected in teaching programmes. The government's recent concern (Department for Education and Employment, 1999) with the teaching of thinking skills may facilitate EPs in this role by providing the education community with an opportunity to reappraise the purposes of cognitive assessment. The authors do not suggest, 
moreover, that the perception of LEA demands of many respondents in this survey reflects any universal picture of LEA attitudes. Questionnaire responses from this small sample of UK EPs indicated perceptions about LEA demands in general, and did not comment on the respondent's own LEA. It may well be that in some Local Education Authority areas, EPs have more active roles, through consultation models, at different stages of the Special Educational Needs Code of Practice, than was suggested by the responses we received, and that such roles might provide scope for the consideration of DA as an alternative assessment model. From the survey, however, it was not possible to identify factors associated with use of DA or lack of uptake in specific contexts.

\section{Difficulty of communicating findings of a DA}

A number of respondents indicated that they found that the outcome of a dynamic assessment could be difficult to communicate due to the unfamiliarity to teachers of the language and concepts used. This might contrast, for example, with the situation where the outcomes of a curriculum-based assessment are being communicated, when EPs and teachers can take some common ground for granted. In DA, clarity of communication is especially important since assessment and intervention are seen as aspects of a single process. In the DA model the interactive assessment sets in motion changes which continue in the teaching context. Interventions that indicate that a DA will be beneficial to a child must be implemented if there is to be any point to the exercise. In some cases a challenge may well be posed for the EP in communicating, usually in the format of an Individual Education Plan, the findings of a form of assessment that will be unfamiliar to Special Educational Needs (SEN) co-ordinators, class teachers and parents. This is an area in which the kind of training and support advocated by the authors in their conclusion could be of assistance. Specific use that may be made of a 
dynamic assessment in contributing to statutory assessment at stage 3 of the Code of Practice is exemplified in Birnbaum \& Deutsch (1996).

\section{A return to 'process-based education'?}

The real challenge, however, may come on a broader front. As one respondent put it, it may be that DA should not be seen 'as just another form of assessment, but as part of a turn, or return, to process-based education'. DA may be considered just one means among others of bringing expertise to bear on the cognitive needs of individual children. Its principles may indeed find a wider application, to whole groups of students, through the use of mediational teaching as a tool for the development of cognitive skills and the fostering of metacognitive awareness as specific educational objectives. Teachers are manifestly concerned with the process of children's learning, in addition to the content of learning. Under the title of 'thinking skills', this concern now also finds government recognition. (Department for Education and Employment, 1999).

Inflated claims for DA must be avoided, however. In itself, it is not 'a total framework for meeting children's needs' (in the words of one respondent). There is no evidence that would justify replacing all other forms of assessment with DA. Haywood (1992), Lidz (1987), Tzuriel (1992) and Samuels (Missiuna \& Samuels 1988), for example, all recommend DA as a complementary form of assessment whose use must be selective. The present authors would argue, however, that DA offers a distinctly different paradigm of assessment which is worth being studied, understood and practised to enable a critical appraisal of its potential uses and disadvantages to be made. It is significant that a large number of respondents who commented about the perceived advantages or drawbacks of DA, were not commenting from the vantage point of experience. They were offering opinions which they themselves acknowledged to be largely based on their theoretical understanding of DA, but not on practitioner experience. 


\section{Issues for evaluation}

One potential outcome of wider training leading to critical use and evaluation, is the possibility of achieving a clearer understanding of the practical benefits of DA. If, as was widely stated in this survey, its theoretical approach is appealing, it does not necessarily follow that the methods which seek to operationalise the theory are successful. If they are successful at a practical level, then we need to understand with which types of presenting problems they are successful.

The DA model most often taught and practised in the UK is that of Mediated Learning, the most individualised of the DA models, and an obvious question is whether this approach is suitable for individual case-work only. How useful might a method that is largely clinical and individual in style prove to be across whole groups of children?

It has been suggested that DA may be especially useful in assessing bilingual children, as well as those from a variety of cultural and ethnic backgrounds. (Usmani, 1999). Indeed, in a number of situations, including disability and disadvantage, in which individual functioning poses challenges to school provision, DA (as many respondents noted) is intuitively appealing as EPs search for approaches that seek to explore learning potential rather than confirm poor current performance. It remains to be tested whether this appeal can be turned into practical and meaningful interventions and advice for parents and educators.

Such evaluations remain to be carried out. The field of DA as a whole still lacks a substantial body of empirical studies. The authors would argue that we are not yet in a position to do more than pose the questions. The answers must wait until EPs in the UK are sufficiently familiar with the theory and practice of DA to undertake the necessary evaluations, and determine whether DA can indeed become one of the EP's range of accessible and practical tools. But adequate training and support would seem to be essential if 
EPs are to have a real choice of approaches to assessment and, in particular, if Dynamic Assessment is to be critically evaluated.

\section{Dilemmas for DA?}

We have noted that what were seen as advantages of DA by some EPs could be seen by others as disadvantages. These contrasting views related to the radically distinct nature of the concepts of assessment used by DA compared with more traditional types of assessment, the necessary continuity of the assessment process with later classroom practice, and the individuality of interpretation which is required by the assessment. It should be borne in mind that many of the responding EPs had not practiced DA, and so their views derived from a theoretical understanding only. It is reasonable to suppose that if the thorough training and follow-up support for which so many respondents indicated a need were provided, perceived disadvantages would for some prove to be simply the result of lack of close familiarity with the practice of DA. Doubts and differences of opinion about DA's whole theoretical perspective and hence of the type of practice that it necessitated, would doubtless remain, however. Doubts can only be resolved one way or another following thorough evaluation of DA by EPs by themselves and this, as the authors argue, is not possible until a larger number are equipped to practice it. Differences of opinion about the purposes of assessment in general reflect deep divisions about the nature of human cognition and can be expected to remain.

\section{Conclusions and recommendations}


The outcome of this research suggests that knowledge of DA deserves to be extended and developed further in the UK than it is at present. The following are offered as possible ways forward:

A commitment on the part of core EP training programmes and Continuing Professional Development programmes to offering substantial training courses in the theories underlying DA and applications of the model, exploring a variety of ways in which DA can be used, interpreted and reported.

Working towards a national standard of training and accreditation of DA courses and post- training supervision, so that criteria of competence for both trainers and practitioners can be achieved. This does not imply that there is one 'right way' of practising DA. This could hardly be so, because (as argued in the introduction) assessment itself, including the range of different DA approaches, is properly seen as just one manifestation of a whole perspective on cognitive development. Nevertheless training cannot simply consist of introduction to such a perspective. It needs to be of sufficient depth to ensure that EPs are able to demonstrate in their practice skilled analysis of cognitive processes and skilled mediational intervention. Such criteria of competence should take into account similar criteria in DA training which are applied overseas, whether offered in specialist centres or by universities, so that competence in the use of DAwould be recognised wherever it was used. This proposal is consistent with initiatives now in progress towards agreeing standards of training for EPs across different European countries.

A more open and exploratory perspective on the part of some EP services and LEAs towards helping children at risk 
of failure. This would imply being prepared to consider increased allocation of time and professional support necessary for [alternative or complementary] assessment approaches such as Dynamic Assessment. As several respondents noted, this may contribute usefully to differentiating and diversifying classroom teaching strategies in schools committed to inclusive education.

This study has shown that while attitudes of British EPs towards Dynamic Assessment are not simple - aspects which are seen as advantages by some may be seen as disadvantages by others - there is also a strong interest in learning more about it, in being given time to use it if it is felt to be appropriate, and in being supported in so doing. Only in these circumstances can the value of Dynamic Assessment be thoroughly tested.

\section{References}

Birnbaum, R. \& Deutsch, R. (1996). The use of Dynamic Assessment and its relationship to the Code of Practice: working across boundaries. Annual Course Proceedings, DECP. Educational and Child Psychology, 13, 3, 14-24.

Buckingham, B.R. (1921). Intelligence and its measurement: a symposium. Journal of Educational Psychology, 12, 271-275.

Budoff, M. \& Corman, L. (1976). Effectiveness of a learning potential procedure in improving problem-solving skills of retarded and non-retarded children. American Journal of Mental Deficiency, 81, 3, 260-264.

Campione, J., Brown, S., Ferrara, A. \& Bryant, N. (1984). The zone of proximal development: implications for individual differences and learning. In B. Rogoff \& J. 
Wertsch (eds.) New Directions for Child Development: Childrens Learning in the Zone of Proximal Development. San Francisco: Jossey-Bass.

Carlson, J.S. \& Wiedl, B.R. (1980). Applications of a dynamic testing approach in intelligence assessment: empirical results and theoretical formulations. Seitshrift für Differeutielle und Diagnostische Psychologie, 1, 4, 303-318.

Department for Education and Employment (1999) From Thinking Skills to Thinking Classrooms: a review and evaluation of approaches for developing pupils thinking. Research Report RR115. Department for Education and Employment.

Feuerstein, R. (1979). The Dynamic Assessment of Retarded Performers: The Learning Potential Assessment Device: theory, instruments and techniques. Baltimore Ma: University Park Press.

Feuerstein, R. \& Feuerstein S. (1991). Mediated learning experience: a theoretical review. In R.Feuerstein, P.Klein \& A.Tannenbaum (Eds.) Mediated Learning Experience: Theoretical, Psychological and Learning Implications Israel: ICELP

Feuerstein, R., Haywood. H.C., Hoffman, M.B. \& Jensen A.R. (1986). Learning Potential Assessment Device Manual. Israel: HWCRI.

Guthke, J. (1995). Recent research evidence on the validity of learning tests. In J. Carlson (ed.). Advanced Cognition and Education Practice Vol 3 (Chap 3). JAI Press

Guthke, J. \& Wingerfeld, S. (1992). The learning test concept: origins, state of the art and trends. In H.C. Haywood \& D.Tzuriel (eds.). Interactive Assessment. Springer.

Haywood, H.C. (1992). Interactive Assessment. Journal of Special Education, 26, 3, 233-234.

Haywood, H.C. \& Tzuriel, D. (eds.) (1992). Interactive Assessment. Springer. 
Imich, A. (1999). Educational psychologists and the allocation of time. Educational Psychology in Practice, 15, 2, 89-97.

Kahn, R.(1992) The Dynamic assessment of Infants and Toddlers. Hartford Court Family Development Resource Centre.

Lidz, C. (1987). Dynamic Assessment: An Interactional Approach to Evaluating Learning Potential. New York/London: Guildford Press.

Lidz, C. (1991). Practitioners Guide to Dynamic Assessment. New York/London: Guildford Press.

Missiuana, C. \& Samuels, M. (1988). Dynamic Assessment: review and critique. Special Services in the Schools, 5, 1, 2, 1-22.

Paour, J.L. (1992a). Piagetian approaches to mental retardation: hopes, barriers, opportunities and convergences. In J.Carlson (ed.). Advances in Cognition of Educational Practice Vol $A(\mathrm{p} 87-111)$. JAI Press.

Paour. J.L. (1992b). Induction of logic structures in the mentally retarded: an assessment and intervention instrument. In H.C Haywood \& D.Tzuriel (eds.) (1992). Interactive Assessment. Springer.

Stringer, P., Elliot, J. \& Lauchlan, F. (1997). Dynamic Assessment and its potential for educational psychologists Part 2: The zone of next development? Educational Psychology in Practice, 12, 4, Jan 1997.

Thomson, L. (1998). A national survey of Scottish educational psychologists: work practices and perceptions. Educational Psychology in Practice, 14, 3, 156-166.

Tzuriel, D. (1992) The Dynamic Assessment approach: a reply to Frisby \& Braden Journal of Special Education 26, 3, 302-324 
Tzuriel, D. (1997a). The relation between parent-child MLE interactions and childrens cognitive modifiability. In A. Kozulin,. (ed.). The Ontology of Cognitive Modifiability. Israel: ICELP.

Tzuriel,D.(1997b) A novel dynamic assessment approach for young children: major dimensions and current research. Educational and Child Psychology.Vol.14,(4)

Usmani, K. The influence of racism and cultural bias in the assessment of bilingual children .Educational and Child Psychology, Vol.16, (3)

Vygotsky, L.S. (1986). Thought and Language. Cambridge Mass./London: MIT Press. 
